\title{
Exploring Negative Transfer in Chinese Students' English Writing at Lexical Level
}

\author{
Jiezhen Niu \\ Beijing Union University \\ Beijing, China
}

\author{
Han $\mathrm{Ji}^{*}$ \\ Beijing Union University \\ Beijing, China \\ *Corresponding Author
}

\begin{abstract}
This study is aimed at an investigation of Chinese college students' writing, with focus on the negative transfer of native language at lexical level. The data is collected from essays written by two groups of non-English majors with different English proficiency levels. A classification as well as its exemplification is offered concerning all these lexical transfer errors. The cause of formation is also analyzed for the corresponding class of language transfer. For this reason, EFL teachers may find the results of this study useful, and they are advised to take countermeasures to help improve students' writing competence.
\end{abstract}

Keywords-negative transfer; English writing; Chinese students; at lexical level

\section{INTRODUCTION}

Writing is a comprehensive manifestation of one's knowledge and can fully reflect his or her language level (Skehan1998; Ellis \& Barhuizen 2005). When Chinese college students learn English writing skills, transfer is manifested at various levels such as lexis, syntax and discourse. Lexical transfer is a kind of cross-linguistic influence in lexicon. Kellerman comments "there are enormous quantities of evidence for the influence of L1 on IL when it comes to lexis" (1987:42). The concept of "lexis" here covers a wide range including words, phrases and collocation. English learners of China tend to make lexical errors or produce semantically anomalous expressions due to the negative lexical transfer from native language. In other words, negative transfer at lexical level has been a problematic issue in English teaching and learning in China, and become one of the major factors affecting students' English proficiency. This paper aims at investigating the errors Chinese students often make, and attempting to find the distribution laws and cause of formation, which may hopefully help teachers understand negative transfer better and promote foreign language teaching.

\section{THEORETICAL FRAMEWORK AND REVIEW OF LITERATURE}

\section{A. The Development of Language Transfer Study}

The impact of first language (L1) on second language (L2) acquisition has been a heated topic all the time. In second language acquisition field, this impact is called native language interference. Some linguists believe that even though language interference can't deal with all the aspects of second language acquisition, nothing can be explained thoroughly without discussing about language transfer. The transfer of native language falls into two kinds: positive transfer and negative transfer. The former improves one's foreign language study, while the latter cramps the study (Odlin, 1989).

Language transfer study has experienced three stages:

- The first stage is that of Behavioral Linguistics. The behavioral language learning theory argues that learning process is the process in which the relation between stimulus and response is established, and new habit is formed when the external conditions function upon the organism. It is for this sake that Lado put forward "Contrastive Analysis Hypothesis" (Lado, 1957). The theory holds that in the process of language acquisition, learners tend to transfer the form, meaning and culture related to their native language into the Second language Acquisition (SLA). The interference of mother tongue is therefore a main obstacle in the process of SLA, and often leads to language errors. As a result, generally, similarities between one's L1 and target language (TL) bring about the positive transfer, while differences between L1 and TL bring about the negative transfer.

- The second stage is that of Universal Grammar. During this period, with the influence of Chomsky's universal grammar, the study of language transfer came into the stage of Interlanguage Hypothesis, during which fundamental changes take place in the understanding of mother tongue transfer (Corder, 1967: 4; Selinker, 1972: 3) and CA theory was challenged a lot. Error Analysis approach overwhelmed and announced the decline of the Contrastive Analysis. According to J. Richard et al. (1974), EA developed as a branch of Linguistics in the 1960's and it came to light to argue that the mother tongue was not the main and the only source of the errors committed by the learners. The aim of EA is, first, to identify strategies which learners use in language learning. Second, to try to identify the causes of learners' errors, that is, investigating the 
motives behind committing such errors as the first attempt to eradicate them. Third, to obtain information on common difficulties in language learning, as an aid to teaching or in the preparation of the teaching materials,

- The third stage is that of Cognitive Linguistics. In this period, the research on language transfer has shifted the perspective of inter-language to the deep interpretation of its generation mechanism. Language transfer in this period is no longer considered to be one language habit replaced with another. Instead, it is a kind of natural psychological development process, which is produced by the cognitive process of language acquisition. With the purpose of studying the language processing mechanism in learner's brain, Processability Theory proposed by Pienemann manages to reveal the restrictive function of language processing ability to language transfer and predict the developmental route of interlanguage. According to this theory, learners can only produce and understand the language forms that can be processed by language processing mechanism in the current state. (Pienemann et al., 2005: 3 14).

\section{B. The Relevant Studies at Home and Abroad}

The theories of Contrastive Analysis Hypothesis, Interlanguage Hypothesis, Error Analysis Hypothesis and Processability Theory put forward by early linguists provide theoretical framework and guidance for research on language transfer, and play a positive role in L2 instruction. Since 1970s, foreign scholars have studied the negative transfer of mother tongue in the English writings of Chinese students. They believe that negative transfer of mother tongue in Chinese students' writing is restricted by Chinese syntax and Chinese culture. And the people who believe negative transfer of mother tongue limited by Chinese syntax are as follows: Schachter (1979) holds that the result of negative transfer of mother tongue at syntactic level in students' writing is decided by the Chinese topicprominence structure. Uzawa (1989) finds that L2 learners often applies L1 thinking in their writing and then translated them into target language; Scollon (1991) proposes that English composition written in indirect way should be explained from different perspectives on selfrecognition in Chinese culture and in western culture. Chinese people's values make it difficult to express their thoughts at the beginning of the article directly. By 1990s, with the development of computer technology, the corpus for second language learners has been set up. Many scholars such as James and Leech started their study on negative transfer of mother tongue in English writing through corpus study.

In the past three decades, more and more Chinese scholars have recognized the necessity of studying mother tongue transfer and carried out empirical studies on the facilitating function of L1( Gu, 1994; Wang, 2000; Dai \&Wang, 2002: 1 9). They claim that the literacy of L1 knowledge has a great impact on SLA (Second Language
Acquisition). The facilitating role played by L1 was further agreed and illustrated by overseas scholars (Gumming, 1987; Kobayashi \& Rinnert, 1992: 23 29). Dai Weidong \& Shu Dingfang find that learners are difficult to get rid of the inherent thinking habits and language structure. The degree of their dependence on mother tongue relies on the difficulty of learning task. If learning task is simple, the dependence will be little. On the contrary, if learning task gets difficult, dependence will become strong. The relationship between them presents a positive correlation (Dai \& Shu, 1994: 1).

\section{RESEARCH DESIGN}

\section{A. Population and Sample}

The population of this study is first year non-English majors at Beijing Union University (BUU). The participants' mother tongue is Chinese, and they have learned English as a foreign language for at least 12 years. With respect to sampling, stratified random sampling is used to obtain 70 students from different majors of Business College. They were divided into two groups of 35 students according to their English proficiency. The participants are taking an English foundation course in the second semester of Academic Year 2017-2018. The 35 high-proficiency learners register for College English Course band-3, whereas the other 35 with lower proficiency take College English Course band-2. An intensive English training program involving spoken English and English writing happen to be held during the same semester has enabled the researcher to teach and collect data from seven classes of 35 students randomly.

\section{B. Research Instruments}

As the present study was aimed at investigating Chinese learners' English writing, the research tool selected is writing task involving letter writing, descriptive essay, argumentative essay, etc. With respect to the learners' knowledge of English writing, all first-year university students are supposed to have had at least some basic paragraph-writing skills. This means the participants should know what a good-quality English paragraph looks like. In the process of data collection, the learners are asked to write the essay in class within 30 minutes. They are informed that they should feel free to naturally produce the written task.

\section{Data Collection}

The data collection is carried out in two phases: (1) In terms of the participant recruitment, 70 first-year undergraduate students from different majors at Business College of BUU were randomly selected and assigned to two proficiency groups as mentioned earlier. (2) Each participant was asked to write seven essays of 120 -word on a topic which was considered easy and possible for them to discuss in writing. The essay is supposed to comprise an introductory paragraph, two or more body paragraphs, and a concluding paragraph. The writing should be finished within 30 minutes in a classroom setting, where learners were not permitted to consult any reference. 


\section{FINDINGS AND DISCUSSION}

Errors exist in different forms, so it is a big challenge to classify the errors in students' English writing. According to the sample writings, lexical errors can be categorized into the following three types: lexical form, lexical meaning, and lexical collocation.

\section{A. Lexical Form}

1) Morphology errors: In this study, morphology errors mainly refer to wrong morphological markers of third-person singular, genitive, plurality, tense and so on. Here are some examples of morphology errors in student's sample writings:

a) It improve (improves) the quality of air and water.

b) Many books can be recycling (recycled).

c) Please stop you (your) damage to our environment.

d) Protecting environment is everyone (everyone's) responsibility.

2) Confusion of lexical category: It is not an easy task for Chinese learners to learn English lexical categories, for it involves knowledge of derivational morphology that does not exist in Chinese. They often get confused with a word's lexical category, and it is likely for them to take an adjective for a noun, a verb for a noun or an adjective for a verb. Error types due to negative transfer of their lexical rule into TL construction are manifested in Chinese learners' English essays. Examples:

a) On the way you come, please careful.

b) Parents are afraid of their children tired, hungry and cold, so they do all the things for them.

\section{B. Lexical Meaning}

1) Assumed semantic equivalence: Unlike young children learning their native language, adult learners have already developed rich conceptual and semantic systems which are already linked to their L1. The acquisition of L2 lexis usually involves a mapping of word form into the preexisted conceptual meanings or L1 translation equivalents as approximations. Ijaz (1986) comments that even advanced adult ESL learners are heavily influenced by native language transfer, which he defines as "semantic equivalence hypothesis". According to the theory, the learner attempts to interpret the new language symbols through his or her accepted language symbols. That explains why L2 learners are likely to develop a strategy of literal translation by seeking word equivalents from his or her native language and establish a direct link with his or her previous experience. Examples:

a) The economic conditions of our company are very poor. (financial)

\section{b) I'd like to have a cup of red tea. (black tea)}

c) The weekend is a good opportunity to loose yourself. (relax) d) The building of environmental-friendly society cannot leave everyone's efforts. (cannot succeed without everyone's efforts).

2) Overuse of general lexis: Channell (1981) takes the overuse of a few "high cover" items as a source of errors in lexical choice. He describes such kind of production as "flat, uninteresting style, and a failure to express the variety of ideas he wants to communicate". The overuse of a certain item can detract the accuracy and properness in L2 writer's expression. The preliminary explanation is that these writers do not master a sufficient amount of vocabulary, for it is witnessed more by the writers under the intermediate level than writers at the advanced level. Yet a deeper insight may attach it at least in part to native language transfer, for every item produced in L2 in this regard resembles an item in L1. Examples:

a) With the technology more and more advancing, the price of cars are much cheaper now, and more and more people can afford to buy a car. But more and more cars bring about more and more troubles, such as more and more traffic accidents, traffic jams, and pollution and so on.

b) Difficulties can make us have rich experience, make us grow stronger, and make us have more courage to go ahead. So I think difficulties are wealth for us, for it makes us mature.

In the above two sentences, when Chinese learners intend to express a tendency of further development, they are quite likely to resort to the English structure "more and more" and "make + complement" structure.

3) Fuzzy paraphrase: When Chinese learners process an idea which they cannot get the expression from their English vocabulary, they may interpret it in their own way, and this is especially true for beginners. Under such circumstances, they may provide a paraphrase of the expression according to its semantic components in their L1 as a means of compensation. Such a paraphrase is generally a process of decomposition of a certain lexical item's semantic components according to the interpretation of that item in Chinese, but such kind of paraphrase is not appropriate in English. Examples: (balloon)

a) The little boy is holding an air ball in his hand.

b) Since carbon dioxide increases in the grand air, the temperature is increasing gradually. (atmosphere)

4) Redundant twins: Chinese learners of English prefer to put together two words close in meaning, especially when they consist of four characters. Such kind of duplication is acceptable in Chinese, and it may sometimes be necessary "to avoid ambiguity, to reinforce meaning, to provide balance and symmetry, or just to satisfy the ear" (Pinkham \& Jiang, 2000), but the presence of two words in Chinese is never in itself a sufficient justification for using redundant twins in English writing. In most cases, when those 
unnecessary words are removed, the English sentence may get clarity and force.

a) If you have any idea or opinion, please tell me face-to-face or e-mail me.

b) We will firmly and resolutely carry out the policy so as to develop our local economy.

\section{Improper Collocation}

The combination of words is not random at all. For instance, tea can be strong, but not heavy, whereas a person can be a heavy drinker but not a strong drinker. Therefore, a L2 learner should know a word by the company it keeps, that is, "the strong patterning in the co-occurrence of words" (Schmitt, 1997:42). When a new lexical item is learned, the learner should also pick up the most common collocations into which the word enters. In students' writings, we find a great number of wrong collocations are directly related to the negative transfer of L1. Examples:

a) The competition is more and more cruel. (fierce)

b) He showed seldom courage in the battle. (rare)

c) If you are convenient tonight, I'd like to invite you for dinner. (free)

In his central paper on collocation, Sinclair (1991) further explains the structural patterning of lexis: the open choice principle and the idiom principle. The open choice principle is essentially a traditional approach to language which stresses the grammaticality, while the idiom principle restricts the choices "not just in a given slot but in the surrounding co-textual slots" (Schmitt, 1997:42). These two principles are complementary, and co-exist in determining the collocation of different lexical items. Examples:

(a) When you feel satisfied about these, you will feel self-respected.

In this sentence, "about" has a high rate of occurrence in English writing, most students use it when they cannot be sure of the right collocation. The right collocation of "satisfy" should be "be/ feel satisfied with", in which the preposition "with" cannot be changed.

(b) In China, an old saying goes, fallen leaves return to the roots, to revert to one's origin.

In this sentence, the mistake is the result of word for word translation from Chinese “俗话说”. While in fact, being an idiom expression, "as" in "As an old saying goes" should not be neglected and omitted.

(c) Mei asked me to receive the phone for her because she didn't want to hear her boyfriend's voice.

In the above sentence, the verb-noun collocation "receive the phone" does not appear suitable to construct a collocation in English. Even though "answer" and "receive" are semantically related in some respects, they cannot be used interchangeably in all contexts. To be more specific, it is undeniable that the verb "answer" collocates perfectly with "phone", whilst "receive" does not.

\section{CONCLUSION}

As can be seen from the present study, students commit a lot of lexical errors in the writing process because of negative transfer of native language, which takes up the highest percentage of the errors made in students' writings. Therefore, it is significant to pay special attention to the negative transfer of native language in English teaching and learning. The pedagogical implications are listed as follows.

\section{A. Proper Attitudes towards Erorrs}

Firstly, students should treat writing errors appropriately. Most of the students consider errors in writing as failures of language learning. When seeing lots of errors in their writings, they may feel frustrated. Actually, errors are unavoidable during the learning process of English writing. If students hold a positive attitude towards errors in writing and take proper measures, gradually their writing proficiency will be improved by language accumulation and self- correction.

\section{B. Appropriate Learning Strategies}

More importantly, teachers can also help prevent students from inappropriate learning strategies with regard to vocabulary. For instance, teachers may make comparison and contrast with different usages of some sample pairs of synonyms, making it a point to them that words being semantically close are hardly interchangeable in all contexts. Besides, teachers may also provide a list of common English collocations that differ from Chinese counterparts, which could, to a certain extent, help learners become aware of a mismatch between collocations in both languages. Moreover, creating good language environment to get students exposed to a large amount of authentic materials will be helpful to reduce the impact from negative transfer of Chinese holistic thinking mode and have a better understanding of English language features.

\section{Paying More Attention to Language Input}

Thirdly, students should enlarge their language input. If word stock is insufficient, writing will become a tough job. Through the investigation, we find that word selection error takes up over $50 \%$ and has become a serious problem for improving English writing skills. Studies show that students can achieve better writing performance with preparation before writing. Therefore, teachers are advised to ask students to read some articles about the topic before they start to write.

\section{Using English-English Dictionary and Reading Original Works}

When students do not know the English equivalent of a Chinese word, the first tendency is to look it up in a bilingual dictionary. However, in most cases, this strategy does not seem to work well for verbs which are quite complicated in use. Therefore, in college English teaching, teachers should encourage students to use English-English dictionary. By referring to a dictionary, students will better command its 
exact meaning, its uses, and the related authentic expressions through English interpretations. Meanwhile, the English examples also provide students with idiomatic English, instead of just Chinese translation. In addition, reading original works in daily study can help students to enrich their language and content in English writing. When students have sufficient input, they will know what to write and how to write.

\section{REFERENCES}

[1] Brown, H.D. Principles of Language Learning and Teaching [M]. Englewood Cliffs, NJ: Prentice Hall Regents. 1994.

[2] Channell, J. Applying Semantic Theory to Vocabulary Teaching [M]. ELTJ 35 (2): 115-22. 1981.

[3] Corder, P. A Role for the Mother Tongue [A]. In Grass, S. and Selinker, L. (eds.), Language Transfer in Language Learning [C]. Newbury: Newbury House, 1983.

[4] Cumming, A. (1989). Writing expertise and second language proficiency. Language Learning, 39, 81-141.

[5] Dai weidong \& Shu Dingfang.(1994). Issues in CA, EA, IA Research. Journal of Shanghai International Studies University. 1:1-7

[6] Dai Weidong \&Wang Dong, (2002) Language Transfer Research: Problems and Reflections. Journal of Foreign Languages.11:1-9

[7] Ellis, R. The Study of the Second Language Acquisition [M]. Oxford: Oxford University. 1994.

[8] Ellis, R.\& G. Barkhuizen. 2005. Analysing Learner Language[M]. Oxford: OUP.

[9] Gu, Yongqi. 1994. Vocabulary learning strategies and language learning outcomes. Paper presented at the International Language in Education Conference in Hong Kong.

[10] Ijaz, I.H. Linguistic and Cognitive Determinants of Lexical Acquisition in a Second Language. Language Learning 36: 401-51. 1986

[11] Joan Pinkham \& Jiang Guihua. The Translator's Guide to Chinglish [M]. Beijing: Foreign Language Teaching and Research Press. 2000.

[12] Odlin.Language Transfer [M].Cambridge:Cambridge University Press, 1989

[13] J.Pinkham \& G.Jiang, The Translator's Guide to Chinglish[M], Beijing, Foreign Language Teaching and Research Press, 2000.

[14] Kellerman, E. Aspects of Transferability in Second Language Acquisition.Unpublished Manuscript, University of Nijmegen. 1987.

[15] Kobayashi, H., \& Rinnert C. (1994). Effects of first language on second language writing: Translation versus direct composition. In A $\mathrm{H}$. Cumming (Ed.), Bilingual performance in reading and writing (pp. 223- 255). Ann Arbor, MI: Research Club in Language Learning.

[16] Lado, Robert. Linguistics Across Culture: Applied Linguistics for Language Teachers[M]. Ann Abor: University of Michigan Press, 1957.

[17] Pienemann, M. (2005). Cross-linguistic Aspects of Processability Theory [M]. Amsterdam:John Benjamins Publishing Co. 2005: 3 14.

[18] Richards, J. C. (1974). Error Analysis: Perspective on Second Language Acquisition[M]. London: Longman Press, 173-181.

[19] Ringbom, H. The Role of the First Language in Foreign Language Learning. Clevedon, Avon: Multilingual Matters. 1987.

[20] Schachter, J. (1974). An error in error analysis. Language Learning [J], 24, 205-14.

[21] Schmitt, N. and McCarthy, M. (eds.) Vocabulary: Description, Acquisition and Pedagogy $[\mathrm{M}]$. New York: Cambridge University Press. 1997.

[22] Scollon, R. \& Wong Scollon 1991, S. Topic confusion in English-Asian discourse [J].World English 10: 113-125.

[23] Selinker, L. (1972). Interlanguage. International Review of Applied Linguistics [J], X: 209-30.
[24] Sinclair, J. Corpus, Concordance, Collocation [M]. Oxford: Oxford University Press. 1991.

[25] Skehan,P.1998. A Cognitive Approach to Language Learning $[\mathrm{M}]$.Oxford:OUP

[26] Uzawa, K., \& Cumming, A. (1989). Writing strategies in Japanese as a foreign language: Lowering or keeping up the standards. The Canadian Modern Language Review, 46, 178-194.

[27] Wang, W .Y.An Investigation into L1 Use in the Writing Process of Tertiary-level EFL Learners in China[D].Unpublished Ph.D.Dissertation.Nanjing University, 2000. 